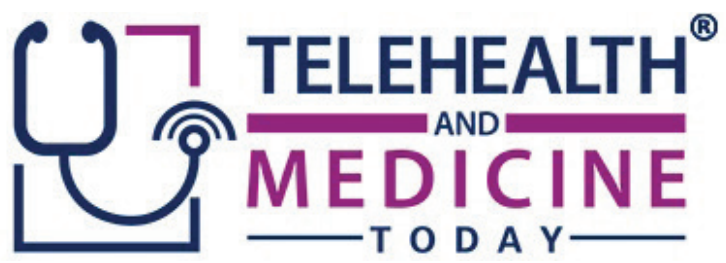

\title{
Role of Telemedicine in Healthcare during the COVID-19 Pandemic in the Developing Countries
}

\section{Muhammad Abdul Kadir}

Affiliation: Department of Biomedical Physics \& Technology, University of Dhaka, Dhaka, Bangladesh

Corresponding Author: Muhammad Abdul Kadir, Email: kadir@du.ac.bd

Keywords: Coronavirus, COVID-19, Developing Countries, e-Health, Mental Health, Primary Healthcare, Public Health, Telehealth, Telemedicine

Section: Use Cases

COVID-19 is a public health emergency of international concern. Ensuring primary healthcare during this pandemic appeared to be a great challenge. Primary healthcare services are being disrupted due to lockdown, lack of protective gears, and hospital facilities, risk of infection spreading to non-COVID patients and health professionals. People with acute and chronic ailments, including diabetes, pregnancy, obesity, chronic respiratory diseases, cardiovascular disease, cancer, and mental health conditions, are facing difficulties in availing primary healthcare services. In this article, the challenges in primary healthcare in the developing countries during the COVID-19 pandemic are analyzed, and the role of telemedicine is discussed in addressing these challenges. Telemedicine can play an important role in this pandemic by minimizing virus spread, effectively utilizing the time of healthcare professionals, and alleviating mental health issues.
Coronavirus disease, caused by $S A R S-C o V-2$ (COVID-19), is a highly infectious disease, declared as pandemic by the World Health Organization (WHO). Around 2.5 million people have been infected by this virus causing more than 175,000 deaths worldwide. ${ }^{1}$ The number of infected people, as well as the death toll, is increasing at an alarming rate. Social distancing is considered effective in reducing the rate of human-to-human transmission and minimizing morbidity and mortality. ${ }^{2-4}$ However, in higher population densities, it is difficult to maintain more than 1-m distance between people as recommended by the WHO. Hence, densely populated developing countries are at high risk of COVID-19 outbreak. $^{5}$

Healthcare systems in low-resource countries face constraints in capacity and accessibility. Hospitals, lacking ventilators, ICU beds, and staff, are not well prepared to handle such a 
pandemic. ${ }^{6}$ There is a scarcity of personal protective equipment (PPE) for health workers. Healthcare professionals are being infected. In this scenario, many hospitals and clinics are reluctant to provide healthcare services, fearing exposure to coronavirus. ${ }^{7}$ As a result, people are deprived of primary healthcare services even with non-COVID illnesses.

However, many acute and chronic ailments, including diabetes, pregnancy, obesity, malnutrition, chronic respiratory diseases, cardiovascular disease, cancer, and mental health conditions, need regular medical advice from doctors. Ensuring primary healthcare needs during this pandemic is a great challenge. Telemedicine and telehealth can play a vital role in ensuring primary healthcare needs in the developing countries during this crisis. Telemedicine is the technology of providing health consultation from a distant place. ${ }^{8}$ In telemedicine, a two-way communication is established between a patient and a doctor, both utilizing the benefit of information and communication technology (ICT).

The doctor, who is at a different remote location from the patient (Figure1), provides health advice and prescription based on the conversation with the patient. The conversation can be audiovisual through video conferencing using smartphones, tablets, or desktop computers. This enables the patient and the doctor to see each other, which gives the impression of a "real" health consultation. In addition, the consultation can occur through audio communication and/or text-messaging using mobile phones. In this article, the challenges in primary healthcare are analyzed in the developing countries during the COVID-19 pandemic, and the utility of telemedicine is discussed in addressing these challenges.

\section{ENABLE HEALTHCARE DURING LOCKDOWN}

Human mobility restrictions can significantly reduce the spread of novel coronavirus infection. ${ }^{10,11}$ The WHO has called on "all countries to continue efforts that have been effective in limiting the number of cases and slowing the spread of the virus." Around 4 billion people, or half of the global population, have been asked to stay at home by their governments to prevent the spread of the deadly COVID-19 virus. However, mobility restrictions have emerged as an obstacle for the patients who suffer from various acute and chronic ailments in visiting medical doctors personally. Not being able to get medical assistance for a long time can increase their health risk. Early intervention can save patients from later complications. Therefore, consultation through telemedicine can be of great help for such patients in maintaining a healthy life during this troubling period.

\section{MINIMIZE INFECTION RISK TO NON- COVID PATIENTS}

In this time of COVID-19 outbreaks, visiting hospitals and clinics increases the risk of infection for patients with non-coronavirus diseases. Diagnostic facilities for COVID-19 are limited in the developing countries due to the lack of testing kits, with many corona positive patients left untested. Many of them are asymptomatic, pre-symptomatic, or very mildly symptomatic. $^{12}$

Even some doctors could be corona positive but untested and asymptomatic. Such asymptotic doctors may also spread infection to the visiting patients. This poses a much high risk of infection for patients with non-coronavirus health ailments visiting hospitals or healthcare facilities. Therefore, treating non-coronavirus diseases through telemedicine systems can significantly reduce the risk of spread of infection to both 


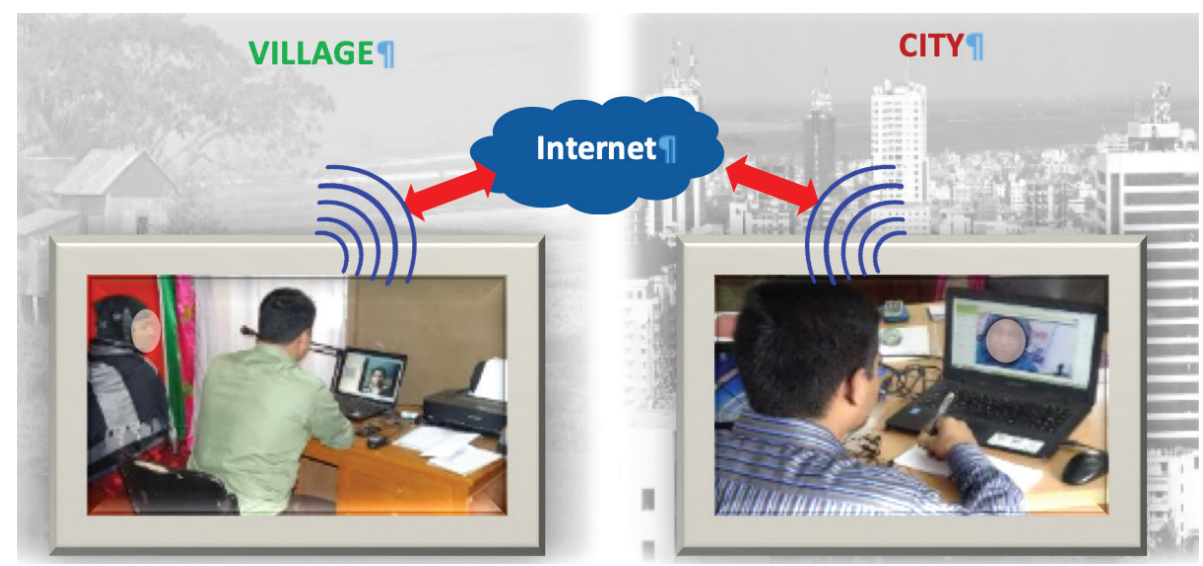

Figure 1-Telehealth consultation using the internet while the doctor and patient are at different locations. ${ }^{9}$

patients and healthcare professionals. Moreover, the majority of corona positive patients do not need to be admitted to hospitals, as the symptoms are very mild. Health consultation through telemedicine could be more effective for such corona positive patients as this will reduce spread of infection. More importantly, telemedicine can reduce the use of PPEs, making these available for healthcare professionals working with severely infected coronavirus patients in hospitals.

\section{EFFECTIVE USE OF DOCTOR'S TIME}

Many healthcare professionals are being infected by COVID-19 over the course of their duties in hospitals and clinics as they are highly exposed to hazards. These infected professionals are required to stay isolated or quarantined at home. Therefore, the valuable time of such doctors is of no use in a situation when it is highly needed. However, these home-quarantined doctors can utilize their time effectively by providing healthcare consultation to patients through telemedicine.

\section{OPTIMIZE DOCTORS' WORKLOAD}

In many developing countries such as India, Bangladesh, and Pakistan, the majority of population lives in rural areas. However, there is a lack of qualified doctors in villages because most of the doctors are city-centric, leading to a geographic imbalance in doctor's availability. Telemedicine services can minimize this geographic imbalance of doctors' workload. Importantly, severity of the COVID-19 infection is not equal in all countries of the world even it is not spread equally in all regions of a particular country. Therefore, telemedicine can help optimize the doctors' workload as any doctor can provide primary health consultation beyond geographic boundaries.

\section{RELIEVING MENTAL STRESS}

Worries and anxiety about COVID-19 and its impact is stressful. ${ }^{13}$ Many people are at risk of mental health problems, including depression. Social distancing makes it more challenging. Psychiatric consultation though telemedicine while staying at home can be very effective in fighting mental health conditions during this pandemic. ${ }^{14}$

\section{CONCLUSIONS}

COVID-19 is a public health emergency of international concern. Telemedicine can play an 
important role in this pandemic by minimizing virus spread, utilizing the time of healthcare professionals effectively, and in alleviating mental health issues. Many areas of the developing countries are covered by mobile network and the internet.

Although limited, some countries are using the internet and cellular connectivity to provide virtual healthcare services. ${ }^{15,16}$ However, in general, people in the developing countries are not very aware of telemedicine and its practical benefits. Developing countries must implement telemedicine services on a large scale and make people aware of its benefits.

Telemedicine systems with video conversation and integrated diagnostic devices (e.g., electronic stethoscope, thermometer, blood pressure, glucose measurement, and electrocardiogram) for common diseases can be more useful. ${ }^{9}$ Use of artificial intelligence and computer-aided diagnosis ${ }^{17,18}$ can also play an important role in diagnosis of disease, thus aiding doctors in providing proper health consultation.

The inability to consult doctors physically has emerged as a great challenge for patients seeking medical assistance. Therefore telemedicine need to be considered as an effective medium of healthcare to minimize the fear of dying without treatment and to make healthcare services easily available to general public during such global crisis.

Acknowledgments: The Swedish International Development Cooperation Agency (Sida) through the International Science Programme (ISP), Uppsala University is acknowledged for financial support.

Contributor's Contributions: Muhammad Abdul Kadir is the sole author of this article.
Conflict of interests: The author declares no conflicts of interest.

\section{REFERENCES}

1. World Health Organization. Coronavirus disease 2019 (COVID-19): Situation report-94 [Internet]. 2020 [cited 2020 Apr 24]. Available from: https://www. who.int/emergencies/diseases/novelcoronavirus-2019/situation-reports

2. Chen S, Yang J, Yang W, Wang C, Bärnighausen T. COVID-19 control in China during mass population movements at new year. Lancet. 2020;395(10226):764-6.

3. Wilder-Smith A, Freedman D. Isolation, quarantine, social distancing and community containment: Pivotal role for old-style public health measures in the novel coronavirus (2019-nCoV) outbreak. J Travel Med. 2020;27(2):taaa020. https:// doi.org/10.1093/jtm/taaa020.

4. Poletti P, Caprile B, Ajelli M, Pugliese A, Merler S. Spontaneous behavioural changes in response to epidemics. J Theor Biol. 2009;260(1):31-40.

5. Rocklöv J, Sjödin H. High population densities catalyse the spread of COVID19. Journal of Travel Medicine. 2020 Apr;27(3):taaa038.

6. Ma X, Vervoort D. COVID-19 and the critical shortage in critical care. Global Health Now. 2020. J Trav Med. 2020;27(3):taaa037. https://doi.org/10.1093/ $\mathrm{jtm} / \mathrm{taaa} 037$.

7. The Philadelphia Inquirer. Nursing homes fear accepting patients who may have coronavirus exposure in hospitals [Internet]. 2020 [cited 2020 Apr 24]. Available from: https://www.inquirer. $\mathrm{com} /$ health/coronavirus/coronavirusnursing-homes-admissions-discharge-pittpennharvard-20200327.html

8. Weinstein RS, Lopez AM, Joseph BA, et al. Telemedicine, telehealth, and mobile health applications that work: Opportunities and barriers. Am J Med. 2014;127(3):183-7. 
9. Rabbani KS, Al Amin A, Tarafdar Z, et al. Dhaka University Telemedicine Programme, Targeting HealthcareDeprived Rural Population of Bangladesh and Other Low Resource Countries. In: Stephanidis C, editor. HCI International 2019 - Late Breaking Papers. HCII 2019. Lecture Notes in Computer Science, vol 11786. Cham: Springer; 2019.

10. Fang H, Wang L, Yang Y. Human mobility restrictions and the spread of the novel coronavirus (2019-nCoV) in China [Internet]. Report No.: 0898-2937. National Bureau of Economic Research; 2020 [cited 2020 Apr 24]. Available from: https://doi. org/10.1101/2020.03.24.20042424.

11. Lau H, Khosrawipour V, Kocbach P, et al. The positive impact of lockdown in Wuhan on containing the COVID-19 outbreak in China. J Trav Medicine, 2020;27(3): taaa037, https://doi.org/10.1093/jtm/ taaa037.

12. World Health Organization (WHO). Coronavirus disease 2019 (COVID-19) situation report-73 [Internet]. [cited 2020 Apr 24]. Available from:https://www. who.int/docs/default-source/coronaviruse/ situation-reports/20200402-sitrep-73covid-19.pdf?sfvrsn=5ae25bc7_2

13. Thakur V, Jain A. COVID 2019-suicides: A global psychological pandemic. Brain Behav Immun. 2020. https://doi.org/10.1016/j.bbi.2020.04.062 [Epub ahead of print].

14. Bashshur RL, Shannon GW, Bashshur N, Yellowlees PM.The empirical evidence for telemedicine interventions in mental disorders. Telemedicine and e-Health. 2016;22(2):87-113.

15. Webster P. Virtual health care in the era of COVID-19. Lancet. 2020;395(10231):1180-1.

16. Combi C, Pozzani G, Pozzi G. Telemedicine for developing countries. Appl Clin Inform. 2016;7(04):1025-50.

17. Chowdhury ME, Rahman T, Khandakar A, et al. Can AI help in screening viral and COVID-19 pneumonia? arXiv preprint arXiv:2003.13145, 2020.

18. Rahman T, Chowdhury ME, Khandakar A, et al. Transfer learning with deep Convolutional Neural Network (CNN) for pneumonia detection using chest X-ray. Applied Sciences. 2020;10(9):3233.

Copyright Ownership: This is an open access article distributed in accordance with the Creative Commons Attribution Non-commercial (CC BY-NC 4.0) license, which permits others to distribute, adapt, and enhance this work non-commercially, and license their derivative works on different terms, provided the original work is properly cited and the use is noncommercial. See:http://creativecommons. org/licenses/by-nc/4.0. 